\title{
Retrospective Evaluation of Patients Leaving Against Medical Advice from Intensive Care Unit (ICU) in Tertiary Care Teaching Hospital
}

\author{
Adhikari K, Devkota K, Yadav RK, Sah R \\ Department of Anaesthesia and Critical care, College of Medical Sciences, \\ Bharatpur, Nepal
}

Received: January 15, 2021

Accepted: March 25, 2021

Published: April 30, 2021

Cite this paper:

Adhikari K, Devkota K, Yadav RK, Sah R. Retrospective Evaluation of Patients Leaving Against Medical Advice from Intensive Care Unit (ICU) in Tertiary Care Teaching Hospital. Nepal Journal of Medical Sciences. 2021;6(1):2-7. http://dx.doi.org/10.3126/njms.v6i1.36724

\begin{abstract}
Introduction: Leaving Against Medical Advice (LAMA) can cause a state of dilemma among the treating physician whether to continue the treatment or to de-escalate from the treatment. It can deteriorate the primary disease of the patient, leading to an increase rate of re-admission to the hospital, increased morbidity and mortality. This is a worldwide phenomenon and the prevalence of LAMA varies between various countries and between different region, religion, and the socioeconomic status of the patient in the same country.
\end{abstract}

Methods: The hospital records from 1st December 2018 to 30th November 2019 of a tertiary care teaching hospital were studied. Patient demography, disease characteristics and length of ICU stay and the factors leading to LAMA were noted and statistically analysed.

Results: During the study period, $14.5 \%$ of patients asked for LAMA. The mean age was 51.22 \pm 22.39 years (range 8 months to 97 years) with Male predominance $(n=288,62.60 \%)$ over Female $(n=172,37.39 \%)$. Patients residing in rural areas were $56.08 \%(n=258)$ and $63.91 \%$ were financially dependent on others for their living. The mean length of stay in hospital was $3.02 \pm$ 3.50 days while $30.86 \%$ of patients required mechanical ventilation. About $51.73 \%$ of patients taking LAMA were admitted from the Internal medicine department. Around $79.56 \%$ were Hindus, with $54.34 \%$ opting for LAMA due to financial restrain followed by poor prognosis $(22.60 \%)$.

Conclusion: The large number of patients admitted in ICU opts out for LAMA. This necessitates formulation and implementation of strategies to reduce the prevalence of LAMA discharge so that patient gets the optimum level of care and the burden in the health care system is reduced.

Keywords: Intensive Care Unit (ICU); Leaving Against Medical Advice (LAMA); Prevalence Rate

Correspondence to: Dr. Kiran Adhikari

Department of Anaesthesiology and Critical Care

College of Medical Sciences (COMS)

Bharatpur, Chitwan, Nepal

Email: kiranadhikari1@gmail.com

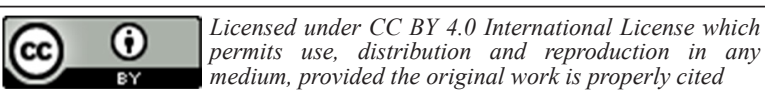




\section{INTRODUCTION}

LAMA is a common way of abandoning medical treatment in Nepal. Multiple factors may be responsible. The health care policy of Nepal has been influenced by the 1978 Alma Ata declaration to improve the communityoriented program for preventive, promotive and curative health-related issues. ${ }^{1}$ However, only $61.8 \%$ of the Nepalese population have access to health care facilities within 30 minutes, with significant urban $(85.9 \%)$ and rural (59\%) discrepancy. ${ }^{2}$

Although Nepal's Interim constitution of 2007 addresses health as a fundamental right, which states that, every citizen has the right to access basic health services free of cost, out-of-pocket expenditure has remained the principal means of financing health care in Nepal, which accounts for approximately $47 \%$ of total health expenditure in 2009. ${ }^{3,4}$ Out -of -pocket expenditure includes payment for the health service facilities, medicine purchased, laboratories tests and fees for the health care providers. This out-of-pocket payment is made by the individual when receiving medical services. ${ }^{5}$ This prevents a significant number of populations from accessing health care facilities. Among those who seek health care facilities, the unaffordability of the medical expenses, the graveness of the disease, lack of proper communication between the physician and the health care seeker, history of substance abuse and dissatisfaction with the treatment are the common reasons for the patient's withdrawal of treatment before the treating physician recommends for the discharge. ${ }^{6,7,8,9}$ The prevalence rate of LAMA varies from $0.002 \%$ to around $43 \%$ around the world. ${ }^{10,11}$ Once the LAMA is requested by the patient, many treating physician faces the dilemma as to whether to respect the patient's choice for the treatment or to do what actually should be done to the patient for the better outcome. ${ }^{12}$ Patients discharged under LAMA often have incompletely treated disease which leads to increased morbidity, increased incidence of re-admission, higher complication rate which further increases the cost of treatment and increased mortality. ${ }^{13,14}$ LAMA is considered to lead to high-risk events which may proceed to malpractice litigation. ${ }^{11,15,16}$

Thus, avoiding the situation of LAMA whereby the patient will get the optimal level of care will not only benefit the patient but also the health care system. Therefore, we planned to evaluate the record of the patients who Left Against Medical Advice once being admitted to the intensive care unit (ICU).

\section{METHODS}

We conducted a retrospective study on patients who left medical treatment Against Medical Advice (AMA) after being admitted to ICU, in College of Medical Sciences, Bharatpur, Chitwan after being approved by the institutional review committee (IRC Ref. No: 2020-047). All consecutive patients who left Against Medical Advice between $1^{\text {st }}$ December 2018 to $30^{\text {th }}$ November 2019 from the ICUs were included in the study. Once discharge was requested by the patient or the patient's attendant, before the primary disease was treated or before the treating physician planned to discharge, and duly signed the consent form, it was considered that the patient was eligible to be discharged against medical advice. Those patients who were referred to other hospitals by the treating physician were excluded from the study.

The sample size calculation was done based on the study by Paul $\mathrm{G}$ et al. ${ }^{7}$

Prevalence $\mathrm{p}=15 \%$

$\mathrm{n}=\mathrm{z}^{2} \times \mathrm{p}(1-\mathrm{p}) / \mathrm{e}^{2} \quad \mathrm{z}=1.96 \mathrm{p}=0.15$

$=1.96^{2} \times 0.15(1-0.15) / 0.05^{2} \quad \mathrm{e}=0.05$

$=196$

For finite population $\mathrm{N}=3160$ (cases admitted in Intensive Care Unit during the study period)

$\mathrm{N}=\mathrm{n} /\{1+(\mathrm{n} / \mathrm{N})\}$

$=196 /\{1+(196 / 3160)\}$

$=184$

Correcting the sample size $\mathrm{n}=2 \times \mathrm{N}=2 \times 184=$ 369

To find out the total number of patients discharged on LAMA, the records from the ICU were checked and their record files were retrieved and studied in April2020. Thepatient's demographic profile (age, sex, occupation, 
geographic area), personal history, diagnosis, primary department to which the patient was admitted were recorded. Whether the patient was on mechanical ventilator support was also noted. The reason for leaving the hospital prematurely was studied from the patient's record file. Data were recorded, tabulated, statistically analysed using Statistical software SPSS version 16 . The quantitative variables are presented as mean \pm SD (standard deviation) and categorical variables are summarized by absolute frequencies and percentages

\section{RESULTS}

A total of 3160 patients were admitted to ICU from different departments, out of which $460(14.5 \%)$ patients took LAMA. The demographic profile of the patients is outlined in Table 1. The age range of the patients who left against medical advice (LAMA) varied from infant (8 months) to 97 years, the mean age being $51.22 \pm 22.39$ years.

As shown in Table 1, the majority of the patient who took LAMA were male $(62.60 \%$ vs $37.39 \%)$. Most of them belonged to the Hindu community $(n=266,79.6 \%)$, followed by Buddhist $(n=66,14.3 \%)$ and the rest as other communities

Table 1: Demographic profile of Study Population

\begin{tabular}{cc} 
Characteristics & $\begin{array}{c}\text { Number (percentage) } \\
\text { of LAMA patients }\end{array}$ \\
Mean age & $51.22 \pm 22.39$ (years) \\
Gender: & \\
Male & $288(62.60 \%)$ \\
Female & $172(37.39 \%)$ \\
Religion: & \\
Hindu & $366(79.56 \%)$ \\
Buddhist & $66(14.34 \%)$ \\
Christian & $14(3.04 \%)$ \\
Muslim & $10(2.17 \%)$ \\
Others & $4(0.86 \%)$ \\
Urban & $202(43.91 \%)$ \\
Rural & $258(56.08 \%)$ \\
\hline
\end{tabular}

As shown in Table 2., 270(58.69\%) patients were adult followed by 142 (30.9\%) old age group patients. Twenty-two patients (4.8\%) were less than 5 years of age. Around $56.1 \%$ $(n=258)$ were from rural areas whereas 43.9\% ( $n=202)$ were from urban areas. The study population consisted of patients from different occupational backgrounds as shown in table 3.

Table 2. Age distribution of patients

\begin{tabular}{cc} 
Age group & $\begin{array}{c}\text { Number } \\
\text { (percentage) }\end{array}$ \\
\hline Less than 5 years & $22(4.78 \%)$ \\
5 -19 years & $26(5.65 \%)$ \\
20-65 years & $270(58.69 \%)$ \\
More than 65 years & $142(30.86 \%)$ \\
\hline
\end{tabular}

\section{Table 3: Occupation, financial status and mechanical ventilatory support of the patient}

\section{Occupation}

Number (\%)

Profession (full-time job)

$16(3.47 \%)$

The clerical, shop owner, farmer

Skilled worker

$86(18.69 \%)$

Semi-skilled worker

$22(4.78 \%)$

Unskilled worker

$52(11.03 \%)$

Unemployed

$52(11.03 \%)$

Children/ Students

$202(43.91 \%)$

$30(6.52 \%)$

Financial status:

Dependent

$294(63.91 \%)$

Independent

$166(36.08 \%)$

Mechanical ventilation:

Intubated

$142(30.86 \%)$

Non-intubated

$318(69.13 \%)$

Around $43 \%$ of the patients who chose to leave medical treatment against medical advice were unemployed, while only 16 patients $(3.47 \%)$ who took LAMA belonged to full-time profession. Thirty patients (6.52\%) either belonged to pre-school children or were students. Two hundred ninety-four patients (63.91\%) of the patients were dependent on their other family members for the living whereas 166 patients (36.08\%) of the patients were financial independent for their living. As shown in figure 1, More than half of the patients $(n=238,51.73 \%)$ were from the department of Internal Medicine followed by 
Neurosurgery $(\mathrm{n}=110,23.91 \%)$, Nephrology $(\mathrm{n}=48,10.43 \%)$, Paediatrics $(\mathrm{n}=24,5.21 \%)$, cardiology $(\mathrm{n}=18,3.91 \%)$, general surgery $(n=14,3.04 \%)$, orthopaedics $(n=6,1.30 \%)$, and Oromaxillofacial surgery (OMFS) $(n=2$, $0.43 \%)$. The mean length of stay in hospital was $3.02 \pm 3.50$ days.

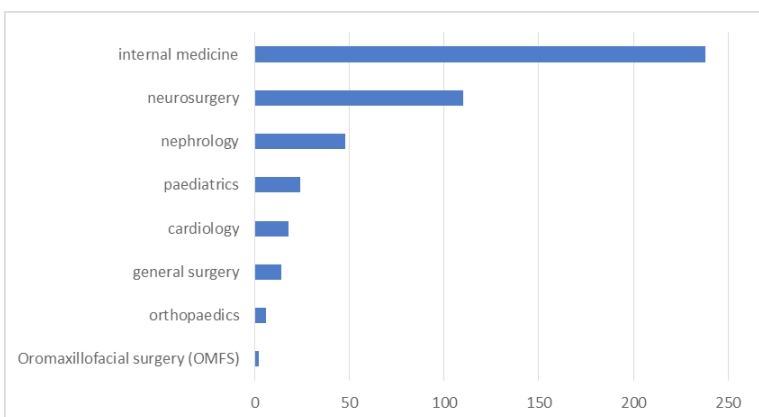

Figure 1: Bar diagram showing the primary department of the patient admitted

Figure 2, shows the reason for opting out of treatment as LAMA in the Nepali population, which was mostly due to financial restriction $(\mathrm{n}=250,54.3 \%)$ followed by poor prognosis $(n=104,22.6 \%)$ of the patients after being explained by the treating physician. Sixtyfour patients $(13.9 \%)$ were taken to other hospitals, 30 patients (6.5\%) took LAMA due to poor prognosis and financial restriction as a combined reason for premature discharge. Six patients (1.3\%) took LAMA as "not being satisfied" by the treatment provided by the hospital, while few patients $(n=2,0.43 \%)$ did not mention the reason for choosing LAMA.

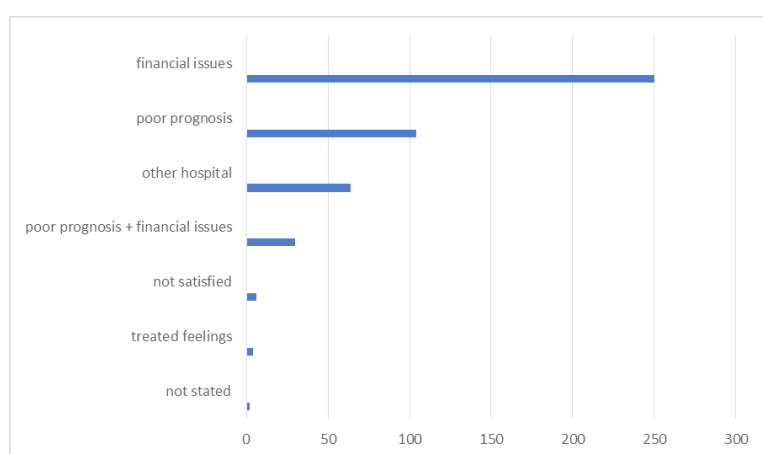

Figure 2: Bar diagram showing the primary cause for LAMA

\section{DISCUSSION}

In this retrospective study, conducted in a tertiary care teaching hospital in Nepal, we found that the overall prevalence of LAMA from the ICU was $14.5 \%$. This is comparable with the study done in North India where they found the prevalence rate of LAMA from ICU was $15 \%$ while other study found $28.8 \%$ of the patients admitted in ICU were discharged on LAMA. ${ }^{7,17}$

Our study had $62.60 \%$ male and $37.39 \%$ female among total LAMA patients. Both the medical and surgical patients were included in the study, and the patients leaving against medical advice from the medical ICU outnumbered those from the surgical ICU. A study done in Iranian tertiary care hospital found their prevalence rate of LAMA were higher than those from developed countries. They included a total of 880 patients, 178 (20.2\%) were discharged against medical advice. Lack of health insurance was found more frequently in patients discharged against medical advice $(46.1 \%$ vs. $34.8 \%) .{ }^{18}$ However we could not co-relate with the lack of health insurance as the cause of LAMA, as we could not trace the records about health insurance facility.

Patients from the different religious background were involved in the study. Around $79.61 \%$ of the patients followed Hinduism. The religious background of the population can differ among various countries, and even in the different locality within the same country. However, none of the communities took LAMA because of religious beliefs.

Among those patients who took LAMA, 142 patients $(30.86 \%)$ were intubated and were on mechanical ventilator support whereas, 318 patients $(69.13 \%)$ did not require ventilatory support. More than half of the study population, $(n=250,54.34 \%)$, opted for LAMA due to financial constrain, followed by $22.60 \%$ of patients with grave prognosis $(n=104)$. This result was similar to the study conducted by Bhoomadevi A et al. ${ }^{19}$ where they found around 50 percent of patients who left against medical advice were due to Financial Constraints. The reason for LAMA can be multifactorial, commonly divided as 
patient-related factors and hospital-related factors. In a study done by Gautam $\mathrm{N}$ et al. ${ }^{17}$ the authors describe the other less discussed and less studied reason for LAMA, as doctors promoting the patients to get discharged on LAMA, to avoid any unwanted legal issues that may arise during the course of treatment or regarding the possible outcome of the patient. However, Patrick J. Devitt has examined whether discharging patients against medical advice protects physicians from malpractice charges, and came to the conclusion that good clinical practice and thorough documentation should be maintained which serves as the best legal protection. discharging a patient against medical advice may provide some protection, but it cannot be considered as a process to avoid legal issues. ${ }^{20}$

The limitation of this study, being a retrospective study, we could not collect all the data that could have been relevant in this study such as having a health insurance policy, education level of the patient and the financial status of the family.

An in-depth knowledge about the factors that lead to LAMA and a systematic approach, to address those issues can improve the health care facility. It not only helps to deliver good health care to the patient but also relieves the situation of conflict between the health care provider and the receiver.

\section{CONCLUSION}

LAMA is a worldwide phenomenon and will continue to be a part of the health care problem. It varies between different countries and even in different regions, religion and socioeconomic status in the same country. In Nepal, the number of patients getting discharged from LAMA is high. Therefore, a proper understanding of the factors that leads to LAMA is of utmost importance. New plans should be formulated and implemented in such a way that it reduces the prevalence rate of patients being discharged on LAMA. Nation wise implementation of health care insurance policy, proper communication between doctors and the patients and easy access to the health care facility will help to decrease the rate of LAMA in our country.

\section{CONFLICT OF INTEREST}

None

\section{SOURCES OF FUNDING}

None

\section{REFERENCES}

1. Cueto $\mathrm{M}$. The origins of primary health care and selective primary health care. Am J Public Health. 2004;94(11):186474.

AJPH.94.11.1864

https://doi.org/10.2105/

2. Simkhada B, Van Teijlinger ER, Porter M, Simkhada P. Major problems and key issues in Maternal Health in Nepal. Kathmandu Univ Med $J$ (KUMJ). 2006;4(2):258-63. Available from: http:// www.kumj.com.np/issue/14/258-263. pdf [Accessed 1st March 2021]

3. Interim constitution of Nepal 2063 (2007) (repealed) [Nepal], 15 January 2007, Available from: https://www. refworld.org/docid/46badd3b2.html [Accessed 25th February 2021]

4. Ministry of health and population, Government of Nepal (2008). Nepal Health Sector ProgrammeImplementation Plan II (NHSP- IP 2): 2010-2015. Kathmandu: MOHP. Available from: https://dohs.gov. np/wp-content/uploads/chd/NHSP/ Consolidated NHSP2 IP.pdf [Accessed 30th February 2021]

5. Ministry of health and population, Government of Nepal (2010), Department of Health services, Annual report 2008/2009. Kathmandu: DoHS. Available From : https://dohs.gov.np/ wp-content/uploads/2014/04/Annual Report 2066 67.pdf [Accessed 15th February 2021]

6. Naderi S, Acerra JR, Bailey K, Mukherji $\mathrm{P}$, Taraphdhar $\mathrm{T}$, Mukherjee $\mathrm{T}$ et al. Patients in a private hospital in India leave the emergency department against 
medical advice for financial reasons. Int J Emerg Med. 2014;7(1):1-5. https://doi. org/10.1186/1865-1380-7-13

7. Paul G, Gautam PL, Khullar R, Paul BS. Prospective evaluation of patients leaving against medical advice of a tertiary care hospital: Comparision of Emergency and Intensive care units. Int $J$ Med. Public Health. 2018;8(1):18-23. https:// doi.org/10.5530/ijmedph.2018.1.4

8. Jeong J, Song KJ, Kim YJ, Cho JS, Park JO, Lee SC et al. The association between acute alcohol consumption and discharge against medical advice of injured patients in ED. Am $J$ Emerg Med. 2016,34(3):464-8. https://doi. org/10.1016/j.ajem.2015.11.065

9. TiL.Leaving the hospitalAgainstMedical Advice among people who use illicit drugs: A systematic Review. Am J Public Health. 2015;105(12):e53-9. https://doi. org/10.2105/AJPH.2015.302885

10. Eze B, Agu K, Nwosu AJ. Discharge against medical advice at the tertiary center in southeastern Nigeria: Sociodemographic and clinical dimension. Patient Intell. 2010;2:27-31. https://doi.org/10.2147/PI.S11337

11. Ti L, Miloy M, Buxton J, Mc Neil R, Dobrer S, Hayashi k et al. Factors Associated with leaving hospital against Medical Advice among people who use illicit drugs in Vancouver, Canada. PLoS ONE. 2015;10(10):e0141594. https:// doi.org/10.1371/journal.pone.0141594

12. Beauchamp TL, Childress JF. Principles of Biomedical Ethics. $5^{\text {th }}$ ed. New York, NY: Oxford University Press; 2001. Available From: https://www. researchgate.net/publication/12869379 Principles_of biomedical_ethics [Accessed 18th February 2021]

13. Glasgow JM, Vaughn-Sarrazin M, Kaboli PJ. Leaving against medical advice (AMA): Risk of 30-day mortality and hospital readmission. $J$ Gen Intern Med. 2010;25(9):926-9. https://doi. org/10.1007/s11606-010-1371-4

14. Southern WN, Nahvi S, Arnsten
JH. Increased risk of mortality and readmission among patients discharged against medical advice. Am $J$ Med. 2012;125(6):594-602. https://doi. org/10.1016/j.amjmed.2011.12.017

15. Alfandre DJ. "I'M Going Home": Discharges Against Medical Advice. Mayo Clin Proc. 2009;84(3):255-60. https://doi.org/10.4065/84.3.255

16. Manoucher J, Goodarzynejad H, Khoshgotta Z, Fatholla MS, Abyaneh MA. Discharge against medical advice among inpatients with heart disease in Iran. J Teh Univ Heart Ctr. 2012;7(2):727. Available from: https://pubmed.ncbi. nlm.nih.gov/23074641/[Accessed 25th February 2021]

17. Gautam N, Sharma JP, Sharma A, Verma V, Arora P, Gautam PL. Retrospective evaluation of patients who Leave Against Medical Advice in a tertiary care institute. Indian $J$ Crit Care Med. 2018;22(8):591-6. https://doi. org/10.4103/ijccm.IJCCM_375_17

18. Shirani F, Jalili M, Asl-E-Soleimani H. Discharge against medical advice from emergency department: results from a tertiary care hospital in Tehran, Iran. Eur $J$ Emerg Med. 2010;17(6):318-21. $\quad$ https://doi. org/10.1097/MEJ.0b013e3283334ef1

19. Bhoomadevi A, Baby TM, Keshika C. Factors influencing discharge against medical advice (DAMA) cases at a multispecialty hospital. J Family Med Prim Care. 2019;8(12):3861-4. https:// doi.org/10.4103/jfmpc.jfmpc $797 \quad 19$

20. Devitt PJ, Devitt AC, Dewan M. An examination of whether discharging patients against medical advice protects physicians from malpractice charges. Psychiatr Serv. 2000;51(7):899-902. https://doi.org/10.1176/appi.ps.51.7.899 